\title{
Preparation and Characteristics of Activated Carbon from Wood Bark and Its Use for Adsorption of $\mathrm{Cu}$ (II)
}

\author{
Jiahui ZHANG, Wenbo ZHANG* \\ MOE Key Laboratory of Wooden Material Science and Application, Beijing Forestry University, Beijing 100083, China \\ crossref http://dx.doi.org/10.5755/j01.ms.20.4.6400
}

Received 07 February 2014; accepted 21 April 2014

\begin{abstract}
In this study, wood bark activated carbon (bark activated carbon, BAC) were prepared by the method of steam activation at the activation temperature of $700^{\circ} \mathrm{C}$ and $800^{\circ} \mathrm{C}$. The pore structures of BAC samples obtained were analysed via means of low temperature nitrogen adsorption. Iodine adsorption value and $\mathrm{Cu}$ (II) ions adsorption capacity were also investigated. The results indicated that micropores and mesopores were abundant in BACs, which indicated a better adsorption effect in iodine and $\mathrm{Cu}$ (II) ions adsorption capacities than wood bark carbon. The efficiency for the removal of $\mathrm{Cu}$ (II) ions were carried out as a function of contact time. The optimal dosage of $\mathrm{Cu}$ (II) ions by BAC700 and BAC800 samples is $5 \mathrm{~g} / \mathrm{L}$ with an optimal time of $30 \mathrm{~min}$. The kinetic studies of BACs revealed a better correlation with the Lagergren pseudo-second order model.

Keywords: wood bark, activated carbon, pore structure, heavy metals removal, copper ions.
\end{abstract}

\section{INTRODUCTION}

As one of the main types of biomass resources, wood bark has a great of importance as forestry residues. The gross production of wood in China reached 81 million cubic meters last year [1], in which contained about $10 \%$ wood bark. This great level of consumption has resulted in an increase of wood bark every year. At present, wood bark is mainly disposed of through burning or waste disposal, generating atmospheric pollutant, which is very harmful to the environment and human health. Wood bark consists of biomass fibers, which are porous in capillary structure and form alternately narrow spaces form. These distinctive structure and characteristics are advantageous to pore-forming materials. Activated carbon is a type of versatile material with an abundant porous structure, very large specific surface area, strong adsorption ability and easy regeneration, etc. Recent years, environmental pollution problems causing by heavy metal ions, which are known to be poisonous and harmful to people and other living creatures have become a global concern. Heavy metal ions (such as cadmium, copper and nickel ions) can cause serious health and environmental problems. Activated carbons having excellent adsorption capacities have attracted a lot of research interests as they are considered to be promising candidates for heavy metals removal. Currently, activated carbons which mainly produced by coal [2], nutshells [3], algae [4] and any other wood by-products $[5,6]$, are widely used as an absorbent in many industrial areas, especially for the removal of heavy metals in purifying industry waste water. Additionally, more and more researches are focusing on activated carbon preparation from biomass materials on the bases of recycling and sustainable point of view. As the most economical and widely used technique, adsorption has been used for heavy metals removal and offers several

\footnotetext{
* Corresponding author. Tel.: +86-10-6233-7386, fax: +86-10-6233-6061. E-mail address: kmwenbo@bjfu.edu.cn (W. Zhang)
}

advantages such as low cost, high removal capacity, ease of use and flexibility in design and operation [5]. Some sorbents such as zeolite [7], yeast [8] and other porous materials [9] have been applied for heavy metals removal. As of now, there have not been many studies regarding the adsorption capacity of heavy metals removal by using carbonized waste wood bark. From the viewpoints of waste reuse, low cost, and eco-friendly material development, this material may simultaneously solve the following problems: waste disposal, emissions of toxic substances, and low cost biosorbent development for purifying waste water of heavy metal ions.

In this paper, wood bark-based activated carbons (BACs) were prepared by physical activation with steam as the activation agent. In industrial practice, physical activation is used most frequently by burning off raw carbon materials to create micropores. The effects of several characteristics such as $\mathrm{pH}$ and iodine adsorption values of BAC samples have been studied for the purpose of acid-base property and micropore adsorption ability. The adsorption capacities were calculated via means of low temperature nitrogen adsorption. Furthermore, pore structure characteristics and adsorption capacity of BAC samples to $\mathrm{Cu}(\mathrm{II})$ in aqueous solutions were also investigated.

\section{EXPERIMENTAL DETAILS}

\subsection{Materials}

The poplar wood (Populus euramevicana cv. 'I-214') barks in this study were collected from Jiangsu Province, China. The barks were washed with running water and then washed by deionized water several times to remove mineral substances in bark surfaces. This process was continued till the removal of all impurities. The washed barks were then completely dried in a drying oven under the temperature of $80^{\circ} \mathrm{C}\left( \pm 2^{\circ} \mathrm{C}\right)$ for over 12 hours. Then 
the dried barks were made into strips $(10 \mathrm{~cm}$ in length, $3 \mathrm{~cm}$ in width) so as to carbonize fully.

\subsection{Preparation of bark activated carbons}

Wood bark carbon(BC) were obtained through the process of bark carbonization with a heating rate of $5^{\circ} \mathrm{C}$ $\mathrm{min}^{-1}$ from room temperature to $600^{\circ} \mathrm{C}$. Thereafter, BC samples were steam-activated with a steam flow of $4.84 \mathrm{~g} / \mathrm{min}$ at $700{ }^{\circ} \mathrm{C}$ and $800^{\circ} \mathrm{C}$ respectively, with a heating rate of $4^{\circ} \mathrm{C} / \mathrm{min}$. Carbonization and activation processes were both under the protection of nitrogen and respectively continued at the target temperature to $60 \mathrm{~min}$. The BAC samples derived from wood bark in this study are labeled as BAC- $T$, respectively, where $T$ denotes the activation temperature in ${ }^{\circ} \mathrm{C}$.

\subsection{Pore structure area analysis of BAC samples}

The pore structure characteristics were determined with a specific surface area/pore size distribution detector (Autosorb iQ) from nitrogen adsorption and desorption isotherms at $77 \mathrm{~K}$ over a wide relative pressure, $p / p_{0}$, ranging from $10^{-6}$ to 1 . The specific surface area and pore volume were calculated by using the Brunauer-EmmettTeller (BET) method over a relative pressure range of $0.05-0.30$. The average pore diameter was calculated using the data reduction software of the instrument. Before the measurements, all samples were outgassed at $300{ }^{\circ} \mathrm{C}$ for 3 hours with highly pure nitrogen $(99.99 \%)$.

\subsection{Yield analysis}

After activation, yields of BAC samples were calculated according to equation (1). Here, the yield refers to the weight of the activated carbon divided by the weight of carbonized carbon with both weights on a dry basis. The equation was as shown below:

$Y=M / M_{0} \times 100 \%$,

where $M$ is the weight of carbon after activation $(\mathrm{g}), M_{0}$ is the weight of carbon before activation $(\mathrm{g})$.

\section{5. pH value and iodine adsorption value analyses}

The $\mathrm{pH}$ value indicates acid-base property of samples, and iodine adsorption value is a reference index of the adsorption capacity for micropores. Those data were determined according to the national standard of $\mathrm{P}$. R. China (GB/T 12496.7-1999, GB/T 12496.8-1999).

\subsection{Heavy metal adsorption equilibrium experiments}

Heavy metal adsorption equilibrium experiments were conducted for the adsorption capacity of $\mathrm{Cu}$ (II) on activated carbons of wood bark as a function of contact time. BAC samples were triturated and screened to size of 40 meshes. The BAC samples were then put into solutions containing $\mathrm{Cu}$ (II) ions with a concentration of $10 \mathrm{mg} / \mathrm{L}$ with an adsorbent dose of $5 \mathrm{~g} / \mathrm{L}$ for the purpose to remove low-concentration $\mathrm{Cu}$ (II) ions efficiently. The mixed solutions were shaken with a rotation speed of $200 \mathrm{r} / \mathrm{min}$ after adjusting the $\mathrm{pH}$ value to 5.0 by adding $\mathrm{HCl}$ and $\mathrm{NaOH}$ solutions with a concentration of $1.0 \mathrm{~mol} / \mathrm{L}$. The concentrations of $\mathrm{Cu}$ (II) ions in the solutions were determined after continuous shaking for 120 minutes. All the experiments were carried out at room temperature $\left(25^{\circ} \mathrm{C} \pm 2{ }^{\circ} \mathrm{C}\right)$. The copper adsorption capacity of BAC samples was investigated with an atomic absorption spectrophotometer (Varian AA220). During the adsorption, a relative equilibrium was established between the adsorbed metal ions and unadsorbed metal ions in the solution. The removal rates of $\mathrm{Cu}$ (II) ions were calculated by equation (2) shown below:

$$
E=\left[\left(C_{0}-C_{e}\right) / C_{0}\right] \times 100 \% \text {, }
$$

where $C_{0}(\mathrm{mg} / \mathrm{L})$ is the initial concentration of sample solutions, $C_{\mathrm{e}}(\mathrm{mg} / \mathrm{L})$ is the remain concentration of sample solutions. The adsorption capacity of $\mathrm{Cu}$ (II) ions were calculated by equation (3) shown below:

$Q=\left(C_{0}-C_{e}\right) V / M$,

where $V(\mathrm{~L})$ is the volume of solutions, $M(\mathrm{~g})$ is the weight of adsorbent. Pseudo first order and pseudo second order kinetic models are applied in order to understand the adsorption kinetics of copper ions.

\section{RESULTS AND DISCUSSION}

\section{1. $\mathrm{N}_{2}$ adsorption isotherm analysis}

The typical $\mathrm{N}_{2}$ adsorption isotherms obtained for the BACs resulting from steam activation are described in Fig. 1. The plots are presented for BACs activated at different activation temperatures $\left(700^{\circ} \mathrm{C}\right.$ and $800^{\circ} \mathrm{C}$, respectively).

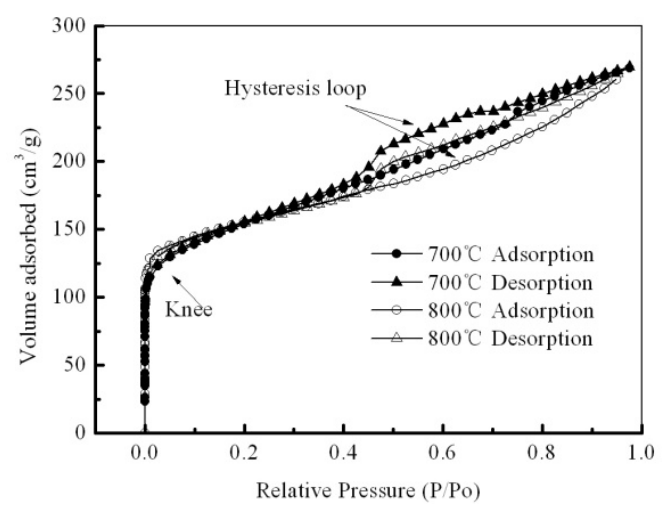

Fig. 1. $\mathrm{N}_{2}$ adsorption-desorption isotherms of BAC samples

From the figure, all these isotherms were increased rapidly in the range of low relative preasure area below 0.1 . Meanwhile, they showed a slow growth in the rest relative preasure range with the appearance of hysteresis loop. Generally, the flatter the isotherm, the more ascendent the micropores were, and vice versa [10]. The isotherms of BACs exactly showed a quite slow upward trend as shown in the figure, which indicated a good micropore and mesopore distribution of BACs prepared [11]. Moreover, the development of pore structure became considerable and similar at the activation temperature between $700^{\circ} \mathrm{C}$ and $800^{\circ} \mathrm{C}$. As can be seen from Fig. 1, with the increase of activation temperature, the amounts of adsorbed volume constantly increased. An obvious inclination of $\mathrm{H} 4$ type of hysteresis loop was observed from the figure around the relative pressure range of $0.4-0.8$, which was considered to be the result of multilayer adsorption phenomenon on 
the surface of the adsorbent and possibly capillary condensation in the mesopores. Ink-bottle pore were possibly formed according to the classification of hysteresis loop by de Boer [12]. Noticeable similarities of BAC samples could be observed in the opening of knee of the isotherms. The knee was open around the volume range of $(100-150) \mathrm{cm}^{3} / \mathrm{g}$ with a relative pressure $\left(P / P_{0}\right)$ around 0.1 , showing a rapid adsorption for $\mathrm{N}_{2}$ onto the micropores. While $P / P_{0}>0.1, \mathrm{~N}_{2}$ began to be adsorbed onto the external surface or large pores, and the amount was considerable. The close pore structure relationships between two BAC samples could be proved in the specific surface area section in Table 1.

\subsection{The specific surface area and pore structure analyses}

Pore structure characteristics and another indexes of samples, which yields based on equation (1), specific surface areas, total volumes, average pore size and iodine adsorption values as a function of temperature are shown in Table 1 . Temperature greatly affected the characteristics of the carbonized wood barks. The yield of BACs were $68.59 \%$ and $54.05 \%$ at the activation temperature of $700{ }^{\circ} \mathrm{C}$ and $800^{\circ} \mathrm{C}$ respectively, which showed an obvious decreasing trend with increasing activation temperature. According to a previous study, greater yield always generated activated carbons with higher microporosity, which might contribute to the continuous microporosity development of wood bark carbonization [13].

Table 1. Characteristics of samples at different temperatures

\begin{tabular}{|c|c|c|c|c|c|c|}
\hline Sample & $\begin{array}{c}\text { Yield } \\
(\%)\end{array}$ & $\mathrm{pH}$ & $\begin{array}{c}I_{\mathrm{a}}^{*} \\
(\mathrm{mg} / \mathrm{g})\end{array}$ & $\begin{array}{c}S_{B E T^{*}} \\
\left(\mathrm{~m}^{2} / \mathrm{g}\right)\end{array}$ & $\begin{array}{c}V_{t}^{*} \\
\left(\mathrm{~cm}^{3} / \mathrm{g}\right)\end{array}$ & $\begin{array}{c}D_{a}{ }^{*} \\
(\mathrm{~nm})\end{array}$ \\
\hline $\mathrm{BC}$ & - & 9.67 & 106.96 & - & - & - \\
\hline BAC700 & 68.59 & 10.62 & 456.12 & 547.65 & 0.47 & 3.46 \\
\hline BAC800 & 54.05 & 12.38 & 498.94 & 555.92 & 0.54 & 1.96 \\
\hline
\end{tabular}

$I_{a}{ }^{*}$ - iodine adsorption value; $S_{B E T}{ }^{*}-$ specific surface area;

$V_{t}^{*}$ - total pore volume; $D_{a v g}{ }^{*}-$ average pore diameter.

As an important index of adsorption ability, pore structure characteristics of BACs were analysed in Table 1. The specific surface area calculated with the BET method $\left(S_{B E T}\right)$ and total pore volume $\left(V_{t}\right)$ of BAC samples increased with the increasing activation temperature. Activation temperature at $700{ }^{\circ} \mathrm{C}$ was found to have significant effect on the development of pore structure for the preparation of wood bark-based activated carbon. The specific surface area had a maximum of $547.65 \mathrm{~m}^{2} / \mathrm{g}$ at $700^{\circ} \mathrm{C}$, which was level off at $800^{\circ} \mathrm{C}$ with $555.92 \mathrm{~m}^{2} / \mathrm{g}$. The loss of BAC samples was probably responsible for the formation of both macroand micropores, resulting in BAC samples with high specific surface areas. Moreover, the activation of wood bark carbon with steam might have been in connection with the $\mathrm{C}-\mathrm{H}_{2} \mathrm{O}$ reaction [10]. This might lead to the removal of carbon atoms thus cause the burn-off, thereby contributing to the development of micropores. However, the average pore diameter $\left(D_{a}\right)$ was decreased with increasing activation temperature in Table 1. This might due to the fracture of intrawalls during carbonizing wood barks. The data showed a trend in the development of micropore $(<2 \mathrm{~nm})$ according to the IUPAC norms [14].
Additionally, as activation temperature increased, the $\mathrm{pH}$ value, which indicates acid-base property of activated carbon, increased with a decrease in yield. The increasing $\mathrm{pH}$ values indicated the alkalinity of alkaline groups containing on the surface of BAC and BC samples. The values increased with the increasing activation temperature. It can be also seen from Table 1 that the iodine adsorption value was $498.94 \mathrm{mg} / \mathrm{g}$ for BAC 800 , which was nearly quintuple than that of $106.96 \mathrm{mg} / \mathrm{g}$ for $\mathrm{BC}$. The data showed a similar trend with the specific surface area of samples. As an indication of the adsorption ability of micropores, the iodine adsorption values of BAC samples increased significantly during the activation process, showing a great development of micropore structure.

\subsection{Heavy metal adsorption equilibrium experiments}

\subsubsection{The effect of contact time on adsorption}

The effect of contact time on the adsorption efficiency of $\mathrm{Cu}$ (II) ions of wood bark samples is shown in Table 2. The adsorption capacity of $\mathrm{Cu}(\mathrm{II})$ ions $\left(q_{t}\right)$ were calculated by equation (3). The data almost presented a same high adsorption trend, showing a good adsorption capacity of $\mathrm{Cu}$ (II) ions. The pore diameters of BAC samples, which microscopic pores were rich, were in the similar order of magnitudes as $\mathrm{Cu}$ (II) ion with a ion radius of about $0.072 \mathrm{~nm}$, resulting in an easier adsorption process of $\mathrm{Cu}$ (II) ions. Also, the alkaline nature with $\mathrm{pH}$ values of $9.67 \sim 12.38$ of the BACs surface was advantageous to $\mathrm{Cu}$ (II) ions removal. From Table 2, it could be found that increase in contact time increased the removal efficiency until equilibrium adsorption was established. As shown in the table, the uptake of BAC samples to $\mathrm{Cu}$ (II) ions increased quickly. The adsorption changes of three samples all became slow only after adsorption $10 \mathrm{~min}$. In $30 \mathrm{~min}$, the process of adsorption quickly reached equilibrium. After this equilibrium period, the amount of adsorbed $\mathrm{Cu}$ (II) ions did not significantly changed with time. From the results it could be observed that $30 \mathrm{~min}$ time was sufficient for attaining the equilibrium for activated carbons from wood barks. The highest removals of copper were $99.19 \%$ by $\mathrm{BC}$ samples, $99.88 \%$ by BAC700 samples and $99.47 \%$ by BAC 800 samples, respectively.

\subsubsection{Kinetic studies based on contact time}

Pseudo-first order and pseudo-second order kinetic models are applied in order to understand the adsorption kinetics of $\mathrm{Cu}$ (II) ions. The pseudo-first order equation of Lagergren is generally expressed as below after integration and applying boundary conditions:

$\log \left(q_{e}-q_{t}\right)=\log q_{e}-\frac{k_{1}}{2.303} t$,

where $t(\mathrm{~min})$ is the contact time, $q_{e}(\mathrm{mg} / \mathrm{g})$ is the amount of solute adsorbed at equilibrium (equation (3)), $q_{t}(\mathrm{mg} / \mathrm{g})$ is the amount of solute adsorbed at time $t$ (equation (3)), $k_{1}\left(\mathrm{~min}^{-1}\right)$ is the rate constant of pseudo-first order sorption.

The pseudo-second order equation of Lagergren is generally expressed as below: 
Table 2. The effect of contact time on sorbent removal efficiency

\begin{tabular}{|c|c|c|c|c|c|c|c|c|c|}
\hline Sample & $t(\min )$ & $C_{t}{ }^{*}(\mathrm{mg} / \mathrm{L})$ & $q_{t}$ & $q_{e l}^{*}$ & $k_{1} *$ & $R_{1}^{2 *}$ & $q_{\mathrm{e} 2} *$ & $k_{2}^{*}$ & $R_{2}^{2 *}$ \\
\hline \multirow{4}{*}{$\mathrm{BC}$} & 10 & 0.410 & 1.918 & \multirow{4}{*}{0.089} & \multirow{4}{*}{0.051} & \multirow{4}{*}{0.900} & \multirow{4}{*}{1.984} & \multirow{4}{*}{2.238} & \multirow{4}{*}{0.999} \\
\hline & 30 & 0.150 & 1.970 & & & & & & \\
\hline & 60 & 0.105 & 1.979 & & & & & & \\
\hline & 120 & 0.081 & 1.984 & & & & & & \\
\hline \multirow{4}{*}{ BAC 700} & 10 & 0.088 & 1.982 & \multirow{4}{*}{0.019} & \multirow{4}{*}{0.029} & \multirow{4}{*}{0.951} & \multirow{4}{*}{1.998} & \multirow{4}{*}{3.271} & \multirow{4}{*}{0.999} \\
\hline & 30 & 0.046 & 1.991 & & & & & & \\
\hline & 60 & 0.029 & 1.994 & & & & & & \\
\hline & 120 & 0.012 & 1.998 & & & & & & \\
\hline \multirow{4}{*}{ BAC 800} & 10 & 0.131 & 1.974 & \multirow{4}{*}{0.016} & \multirow{4}{*}{0.021} & \multirow{4}{*}{0.606} & \multirow{4}{*}{1.990} & \multirow{4}{*}{3.158} & \multirow{4}{*}{0.999} \\
\hline & 30 & 0.085 & 1.983 & & & & & & \\
\hline & 60 & 0.079 & 1.984 & & & & & & \\
\hline & 120 & 0.053 & 1.989 & & & & & & \\
\hline
\end{tabular}

$C_{t}^{*}$ - remain concentration of solutions at time $\mathrm{t} ; q_{\mathrm{e} 1} / k_{1} / R_{1}{ }^{2 *}$ - parameter of pseudo-first order kinetic models; $q_{\mathrm{e} 2} / k_{2} / R_{2}^{2 *}$ - parameter of pseudo-second order kinetic models.

$$
\frac{t}{q_{t}}=\frac{1}{k_{2} q_{e}^{2}}+\frac{1}{q_{e}} t
$$

where $t(\mathrm{~min})$ is the contact time, $q_{e}(\mathrm{mg} / \mathrm{g})$ is the amount of solute adsorbed at equilibrium (equation (3)), $q_{t}(\mathrm{mg} / \mathrm{g})$ is the amount of solute adsorbed at time $t$ (equation (3)).The Lagergren pseudo-first order and pseudo-second order kinetic plot for the adsorption of $\mathrm{Cu}(\mathrm{II})$ ions are shown in Fig. 2.

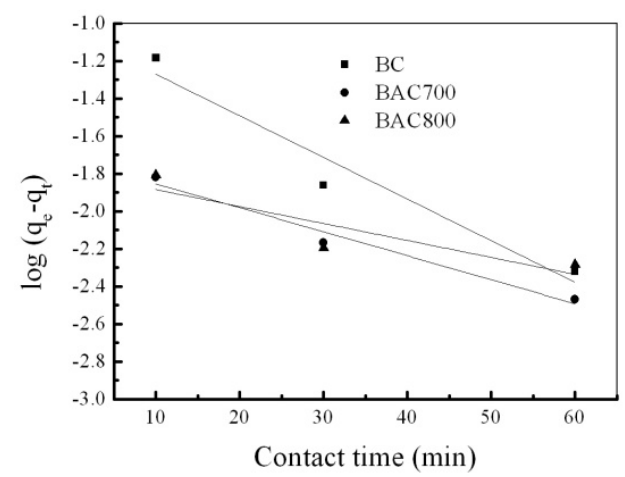

a

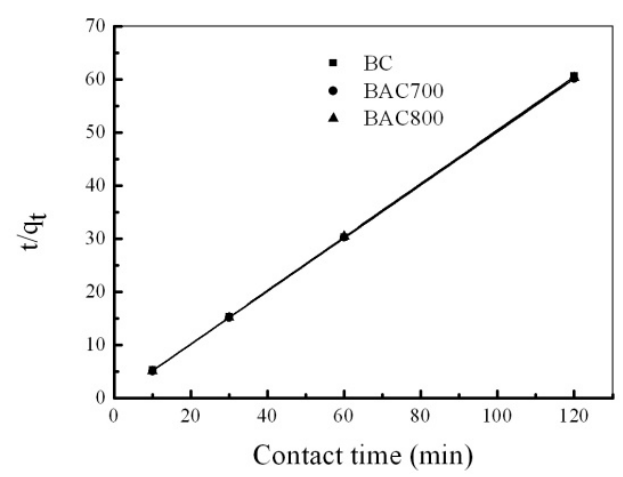

b

Fig. 2. Kinetics of $\mathrm{Cu}$ (II) onto $\mathrm{BC}$ and $\mathrm{BAC}$ samples: a - pseudo-first order kinetics of $\mathrm{Cu}$ (II) onto samples; $\mathrm{b}$ - pseudo-second order kinetics of $\mathrm{Cu}$ (II) onto samples

The parameters of equations $\left(q_{e}, k, R^{2}\right)$ are given in Table 2. As showed in Fig. 2 and Table $2, R^{2}$ and $q_{\mathrm{e}}$ of pseudo-first order kinetic models were lower than those of pseudo-second order kinetic models as dot deviations were large. The deviation showed that the adsorption processes were well represented by the pseudo-second order kinetics, which supports the hypothesis on the basis of model that adsorption was due to chemisorptions. The trend was similar with other kinds of activated carbons [4].

\section{CONCLUSIONS}

In this study, activation was carried out on the wood bark-based carbon, using steam as an activation agent with activation temperature of $700^{\circ} \mathrm{C}$ and $800^{\circ} \mathrm{C}$. Sorption characteristics were analysed by means of low temperature nitrogen adsorption, yield, $\mathrm{pH}$ and iodine adsorption. Moreover, the activated carbons were used as adsorbents for removing $\mathrm{Cu}$ (II) ions from aqueous solution. It was found that yields increased with increasing activation temperature. The results revealed that prepared BAC samples were highly porous. The iodine adsorption values which indicated the abundant micropores in BAC samples increased with increasing surface specific area. Mesopores were also considerable in BAC samples. The resultant activated carbon exhibited a maximum specific surface area of $555.92 \mathrm{~m}^{2} / \mathrm{g}$ for BAC 800 . The contact time of heavy metal adsorption equilibrium experiments was found to be effective on the adsorption efficiency of $\mathrm{Cu}$ (II) ions. The kinetic studies of $\mathrm{Cu}$ (II) ions adsorption revealed a better data correlation with pseudo-second order model than that with pseudo-first order model. It was observed that the percentage removal of $\mathrm{Cu}$ (II) ions increased with increase of contact time, reaching the equilibrium at around $5 \mathrm{~g} / \mathrm{L}$ in $30 \mathrm{~min}$. From the viewpoints of low cost and eco-friendly material development, wood-bark based activated carbon is promising to become biosorbent for removal of low-concentration heavy metal ions in water purification process.

\section{Acknowledgement}

This study was financially supported by the state forestry administration of People's Republic of China through the 948 project (No.2013-4-04). 


\section{REFERENCES}

1. http://www.stats.gov.cn/tjgb/ndtjgb/qgndtjgb/t20130221_40 2874525.htm (Access 12 November, 2013)

2. Prinsloo, F. F., Opperman, D. P., Budeli, J. C., Hauman, D. The Production of Activated Carbon from High-ash Subbituminous and Bituminous South African Coals 16th Annual International Pittsburgh Coal Conference, Pittsburgh, United States Sasol Technology Ltd, Sasolburg (ZA) 6 1999: pp. 697-712.

3. Kirubakaran, C. J., Krishnaiah, K., $\quad$ Seshadri, S. K. Experimental Study of the Production of Activated Carbon from Coconut Shells in a Fluidized Bed Reactor Industrial \& Engineering Chemistry Research 30 (11) 1991: pp. $2411-2416$.

4. Jeyakumar, Suresh, R. P., Chandrasekaran, $\mathbf{V}$. Comparative Studies on the Removal of Copper (II) by Ulva Fasciata Activated Carbon and Commercially Activated Carbon Polish Journal of Chemical Technology 14 (4) 2012: pp. 88-94.

5. Shawabkeh, R., Rockstraw, D., Bhada, R. Copper and Strontium Adsorption by a Novel Carbon Material Manufactured from Pecan Shells Carbon 402002 pp. $781-786$.

6. Witek-Krowiak, A. Application of Beech Sawdust for Removal of Heavy Metals from Water: Biosorption and Desorption Studies European Journal of Wood and Wood Products 71 (2) 2013: pp. 227-236. http://dx.doi.org/10.1007/s00107-013-0673-8

7. Sheta, A. S., Falatah, A. M., Al-Sewailem, M. S., Khaled, E. M., Sallam, A. S. H. Sorption Characteristics of Zinc and
Iron by Natural Zeolite and Bentonite Microporous and Mesoporous Materials $61(1-3)$ 2003: pp.127-136.

8. Yang, H., Xu, R., Xue, X., Li, F., Liu, G. Hybrid Surfactant-Templated Mesoporous Silica Formed in Ethanol and its Application for Heavy Metal Removal Journal of Hazardous Materials 152 (2) 2008: pp. 690-698.

9. Sayar, O., Amini, M. M., Moghadamzadeh, H., Sadeghi, O., Khan, S. J. Removal of Heavy Metals from Industrial Wastewaters Using Amine-Functionalized Nanoporous Carbon as a Novel Sorbent Microchimica Acta $180(3-4)$ 2013: pp.227-233.

10. Zhang, T. Y., Walawender, W. P., Fan, L. T., Fan, M., Daugaard, D., Brown, R. C. Preparation of Activated Carbon from Forest and Agricultural Residues through $\mathrm{CO}_{2}$ Activation Chemical Engineering Journal 105 (1-2) 2004: pp. 53-59.

11. Brunauer, S., Deming, L. S., Deming, W. E., Teller, E. On a Theory of the van der Waals Adsorption of Gases Journal of the American Chemical Society 62 (7) 1940: pp. $1723-1732$.

12. de Boer, J. H. The Structure and Properties of Porous Materials. London, Butterworths, 1958: 68 p.

13. Venkatraman, A., Walawender, W. P., Fan, L. T. Production and Characterization of Activated Carbons from Cereal Grains American Chemical Society, Division of Fuel Chemistry 41 (1) 1996: pp. 260-264.

14. Shiratori, N., Lee, K. J., Miyawaki, J., Hong, S.-H., Mochida, I., An, B, Yokogawa, K., Jang, J., Yoon, S. H. Pore Structure Analysis of Activated Carbon Fiber by Microdomain-Based Model Langmuir 25 (13) 2009: pp.7631- 7637 . 